of nutrition diminished in a corresponding ratio, until it ceased altogether. During the last eighteen days of her life she had lost the power of swallowing. She was therefore emaciated to the last degree, was partially delirious from insufficient sustenation, and she died at the expiration of the fourteenth week from the operation.

An examination revealed extensive ulceration and destruction of the larynx. The epiglottis was partially destroyed; the arytenoid cartilages and ligaments, in fact every distinct landmark of organization above the cricoid cartilage was totally destroyed; so that there was no trace whatever of the rima glottidis or chordæ vocales, and the boundaries separating the cavities of the larynx and trachea were wholly obliterated. The entire surface of the larynx was in a state of ulceration, and was studded with profuse vegetative growths or interstitial depositions. Small bony particles existed in the region of the cricoid cartilage, and one of the horns of the thyroid cartilage which was denuded was seen to be ossified. The anterior walls of the pharynx were destroyed; consequently this cavity and that of the larynx were united, and during the latter days of the patient's life the fluids she attempted to drink passed directly into the trachea and were regurgitated through the canula. The upper portion of the cesophagus was also ulcerated and its orifice very much contracted. The glandular swellings upon the neck were in a state of suppuration. 'The lungs were reduced to a mere handful, but there were no indications of softening; they were evidently in a condition of miliary tubercle.

Greenfield, Dec. 20, 1852.

MEIICA SACRA-EMBALMING OF THE DEAD.

LY DR. THEOPH. RUBINSOHN.

[Continued from page 409.]

But if the body be preserved, the soul which dwelt in it during its life time, remains with it even after its death, and is freed from the penalty of transmigrating into the body of some beast. This notion of transmigration of the soul into animals, gave rise to the idea that the body should be preserved in its natural form; hence, also, the commiseration towards animals, because they were thought to be the owners of human souls, and hence, also, the custom of embalming the dead.

Herodotus describes the following methods of embalming. When one died, the persons who were engaged in the business of embalming exhibited to the relatives of the dead various patterns of wood, which were painted as a dead, embalmed corpse. One pattern was of the finest workmanship, and was called Osiris, a name which one was not permitted to pronounee; the second pattern they exhibited was not so fine nor so expensive; the third pattern was the cheapest. From these three patterns one was selected, and the parties made the bargain. The most expensive embalning cost one talent of silver, about $\$ 1000$; the second, $\$ 300$; and the third was considerably cheaper. The method of embalming was thus :-First they extracted the brain through the 
nostrils with a hook, and filled the head with spices and groceries (pharmaka). The holy scribe (hierogrammateos) then made the sign upon the corpse where the cut for opening it should be made, which the "parachistes" executed by means of the 无thiopian stone, and escaped immediately, as the people threw stones after him, because they considered him who cuts a corpse to be worthy of their indignation and hatred. They then extracted the entrails (yet this was not a general practice), purged the abdomen with a kind of wine prepared from dates, filled it with spices bruised in water, put into it also myryh, and the cut was sown together by means of a needle and thread. The corpse was then laid into nitrum (nitron or litron) where it remained for the space of seventy days. When these days were gone, the body was washed and swaddled in fine linen (byssus), dipped in gum. The relatives then took the body and deposited it in a coffin that was made in the figure of a man, and placed it in an upright position against the wall of a room appointed for that exclusive purpose.

The swaddling of the mummies was in the following manner-all mummies seeming to have been swaddled alike; the only difference was in the number of the cloths and their quality. The body is first dressed in a long shirt, which is tied on the back at the neck. The head is covered with a square napkin of fine materials, which covers also the face as with a mask. Frequently the face was covered with five or six such napkins, of which the first was painted, and represented the countenance of the embalmed body. Every part of the body was tied in separate cloths immersed in a kind of resin. The legs were tied together, the arms crossed on the chest and swaddled in long cloths which surrounded the whole body. The last cloths were painted with hieroglyphic figures, and fastened with long and symmetrically-crossing ribbons, which finished the swaddling. The mummy was then put into a sarcophagus, which had the form of a human figure. Wealthy persons used three coffins, one within another, the outer more sumptuous than the first ones. Kings were put into colossal sarcophagi of oriental granite, and hidden in the catacombs. The more humble classes embalmed their dead relatives in a less expensive manner.

In some mummies objects are found which seem to have reference to the business in which they were engaged during life. Mailet found in one mummy, strings of a musical instrument, from which he infers that the embalmed body was either a musician or a musical-instrument maker.

From what we have said, it is clear that the Egyptians manifested a great aversion against the opening of the dead, since they threw stones after the parachistes who cut the body for the sake of embalming it. They had, therefore, no opportunity of examining the entire structure of the human body, the position and connection of its individual parts in its regular or abnormal condition. The method of opening the corpse was crude, so that science could not profit from it; the brain was extracted through the nostrils with a bent hook ! There are also many historical testimonies of the ignorance of the Egyptians in the elementary sciences of anatomy and physiology. They generally believed that the heart annually increased to the thirtieth year, and then decreased 
in weight as much as it formerly increased, which was the natural consequence of death. It was also believed, that a nerve is extended from the fourth finger of the left hand to the heart, wherefore the religious custom was introduced to dip this finger in the wine at sacrifices. Manetho informs us that a certain king, Athollis or Athosthas, wrote anatomical books ; but he lived, if at all, in the fabulous times, and some historians believe him to have been the Egyptian Hermes. Plinius, indeed, thinks that the Egyptian kings commanded that the dead should be opened, in order that the causes of death should be known; but it is probable that he refers to the Ptolemæan dynasty, in whose time the science of anatomy took its rise. The account of Plutarch, that the Egyptians used to place a "skeletos" in the rooms where they feasted, that the invited guests should remember that they will also die, should be understood in a figurative, not literal sense. Herodotus, who was an eye witness, says that it was a wooden image of a corpse that was placed in the dining saloon, to which the guests were shown, with the words"Look at this, drink and be merry, for after your death you will be like this." Do not the words of the prophet Isaiah (xxii., 13) "Let us eat and drink, for to-morrow we die," refer to the same Egyptian custom?

\section{OPERATIVE SURGERY JLLUSTRA'TFU, BY R. U. PIPER, M.D.}

[Communicated for the Boston Medical aud surgical Journal.]

$M_{\text {ANY months since, the announcement was made in the Boston Medical }}$ and Surgical Journal, that a volume on operative surgery was soon to issue from the Boston press, which promised to be one of much value. As there are already so many standard works on the subject, and some, too, of the highest excellence, it was felt that a new one must possess uncommon merits and entirely new features in order to secure attention, and that the author must possess much confidence to justify the undertaking. We have accordingly waited and watched for the completion of this book, and for further notice of its character.

The secular press has advertised it as ready for sale, and has spoken of it in terms of much praise. The medical journals of New Hainpshire, Buffalo, and Ohio, have given to it special notices, and have bestowed very flattering commendations, and urge it strenuously on the consideration and patronage of the medical profession. Why we should wait so long and go so far for testimonials of the work, is accounted for only, perhaps, by the fact that "A prophet is not without honor, save in his own country."

It is so seldom that works on either medicine or surgery issue from the Boston press, that the greater interest is produced when one does appear; and this interest is increased, too, by the fact that those which it has published have so uniformly proved works of standard merit. The volume under review, will do no discredit to this well-deserved reputation. Dr. Piper has presented us with a vast amount of information, in a form both " available and cheap," and in a shape most convenient for frequent and easy reference. Its title-page reads thus-" Ope- 